Grand Valley State University

ScholarWorks@GVSU

2012

\title{
Does the Importance of Parent and Peer Relationships for Adolescents' Life Satisfaction Vary Across Cultures?
}

\author{
Beate Schwarz \\ University of Basel, beate.schwarz@unibas.ch \\ Boris Mayer \\ University of Konstanz \\ Gisela Trommsdorff \\ University of Konstanz \\ Asher Ben-Arieh \\ Hebrew University of Jerusalem \\ Mihaela Friedlmeier \\ Grand Valley State University, friedlmm@gvsu.edu
}

See next page for additional authors

Follow this and additional works at: https://scholarworks.gvsu.edu/psy_articles

Part of the Psychology Commons

\section{ScholarWorks Citation}

Schwarz, Beate; Mayer, Boris; Trommsdorff, Gisela; Ben-Arieh, Asher; Friedlmeier, Mihaela; Lubiewska, Katarzyna; Mishra, Ramesh; and Peltzer, Karl, "Does the Importance of Parent and Peer Relationships for Adolescents' Life Satisfaction Vary Across Cultures?" (2012). Peer Reviewed Articles. 41.

https://scholarworks.gvsu.edu/psy_articles/41

This Article is brought to you for free and open access by the Psychology Department at ScholarWorks@GVSU. It has been accepted for inclusion in Peer Reviewed Articles by an authorized administrator of ScholarWorks@GVSU. For more information, please contact scholarworks@gvsu.edu. 


\section{Authors}

Beate Schwarz, Boris Mayer, Gisela Trommsdorff, Asher Ben-Arieh, Mihaela Friedlmeier, Katarzyna Lubiewska, Ramesh Mishra, and Karl Peltzer 


\title{
Does the Importance of Parent and Peer Relationships for Adolescents' Life Satisfaction Vary Across Cultures?
}

Beate Schwarz', Boris Mayer², Gisela Trommsdorff ${ }^{2}$, Asher Ben-Arieh ${ }^{3}$, Mihaela Friedlmeier ${ }^{4}$, Katarzyna Lubiewska ${ }^{5}$, Ramesh Mishra ${ }^{6}$, and Karl Peltzer ${ }^{7}$

\author{
Abstract \\ This study investigated whether the associations between (a) the quality of \\ the parent-child relationship and peer acceptance and (b) early adolescents' \\ life satisfaction differed depending on the importance of family values in the \\ respective culture. As part of the Value of Children Study, data from a sub- \\ sample of $N=1,034$ adolescents (58\% female, $M$ age $=13.62$ years, $S D=0.60$ \\ years) from II cultures was analyzed. Multilevel analyses revealed a posi- \\ tive relation between parental admiration and adolescents' life satisfaction \\ independent of cultural membership. Further, the higher the importance

\footnotetext{
'University of Basel, Switzerland

${ }^{2}$ University of Konstanz, Germany

${ }^{3}$ Hebrew University of Jerusalem, Israel

${ }^{4}$ Grand Valley State University, MI, USA

${ }^{5}$ Kazimierz Wielki University of Bydgoszcz, Poland

${ }^{6}$ Banaras Hindu University, Varanasi, India

${ }^{7}$ Human Sciences Research Council, Pretoria, and University of Limpopo, South Africa

\section{Corresponding Author:}

Beate Schwarz, University of Basel, Department of Psychology,

Missionsstr. 62a, 4055 Basel, Switzerland

Email: beate.schwarz@unibas.ch
} 
of family values in a culture, the weaker was the positive effect of peer acceptance on adolescents' life satisfaction. The results highlight the universal importance of parental warmth and support in adolescence and underline the effect of culturally shared family values on the role of peer acceptance for adolescent development.

\section{Keywords}

Parent-adolescent relationships, cross-cultural, family values, life satisfaction, peer relationships

In early adolescence, the onset of fundamental changes is observable in physical, cognitive, emotional, and social development (Collins \& Steinberg, 2006). In a similar vein, life satisfaction undergoes changes across adolescence. Life satisfaction is part of the multifaceted construct of subjective well-being (SWB). SWB refers to people's self-evaluation and includes emotional components such as positive affect and lack of negative affect, and a cognitive component: life satisfaction. Life satisfaction comprises global and domainspecific judgments about one's own life (Diener, Suh, Lucas, \& Smith, 1999). Recent studies have shown that global as well as domain-specific life satisfaction decreases from early to middle adolescence (Casas et al., 2007; Goldbeck, Schmitz, Besier, Herschbach, \& Henrich, 2007). In adult populations, SWB and its facets are predictors of physical and mental health (for a review see Diener, Oishi, \& Lucas, 2003). However, only a few studies have investigated the predictive power of early adolescents' life satisfaction for later development (Huebner, 2004). So far, longitudinal studies including early adolescents have shown negative effects of early adolescent life satisfaction on both externalizing problems (Suldo \& Huebner, 2004a) and internalizing problems (Huebner, Funk, \& Gilman, 2000). Given the importance of early adolescents' life satisfaction for adolescent development, in the present study we aim to investigate factors that contribute to higher life satisfaction.

In general, social relationships affect life satisfaction (Diener et al., 1999). In early adolescence, the relationship with parents starts to change remarkably. Individuation theory underlines that adolescents still need a close and supportive relationship with their parents. Often, the parent-child relationship changes into a less hierarchical, more partner-like relationship (Collins \& Steinberg, 2006). At the same time, early adolescents begin to spend increasingly more time with peers (Larson \& Verma, 1999; Rubin, Bukowski, \& Parker, 2006). A major function of peers in adolescence is to support the individuation process from parents and the adolescents' identity development; this is one reason 
for the increasing relevance of belonging to a peer group and being accepted by the peers (Rubin et al., 2006). Early adolescence is an important but nevertheless understudied period of life for investigating the contributions of the quality of the parent-child relationship and the adolescents' peer group integration to adolescents' life satisfaction.

Some studies support the association between parent-adolescent relationships and adolescent life satisfaction. Based on data of the German household panel on older adolescents, Trzcinski and Holst (2008) showed an association between open and egalitarian communication with mothers and adolescents' life satisfaction. Among United States as well as Spanish youth, support from parents was positively related to adolescent life satisfaction (Casas et al., 2007; Suldo \& Huebner, 2004b). This association was stronger in early adolescence compared to middle and late adolescence (Suldo \& Huebner, 2004b).

There is some evidence that the quality of peer relationships is associated with the life satisfaction of older adolescents (see the review of Huebner, 2004) and for (Spanish) early and middle adolescents (Casas et al., 2007). However, none of the studies have investigated peer-group integration or peer acceptance. In a recent study on older children and early adolescents, Nickerson and Nagle (2004) found negative associations of adolescents' life satisfaction with perceived alienation from parents and alienation from peers. The associations were comparable for boys and girls and for late childhood, preadolescence, and early adolescence. One study investigating the relation between parent and peer attachment and life satisfaction in early adolescence gives a hint on the relative importance of parents versus peers. The association between parent attachment and life satisfaction was higher than the association between peer attachment and life satisfaction for both genders (Ma \& Huebner, 2008).

However, all studies reported are based on Western samples. Given that cultures differ with respect to their cultural values and norms regarding family and peer relationships, one might ask whether these specific social relationships contribute differently to early adolescents' well-being in different cultures (Chen, French, \& Schneider, 2006; Trommsdorff, 2006). Therefore, our study takes a cross-cultural perspective.

Individualism/Collectivism is an often-used cultural dimension for explaining cultural differences (Hofstede, 2001), but there is an ongoing debate regarding this concept. Individualism and collectivism might not represent two ends of a single dimension but instead might be relatively independent. In many cultures one can find elements of both collectivism and individualism (Kagitcibasi, 1994; Triandis, 1994). Furthermore, researchers too often use individualism and collectivism as broad, general concepts 
instead of acknowledging their multifaceted quality (Kagitcibasi, 1994; Triandis, 1994; Oyserman, Coon, \& Kemmelmeier, 2002). This is underlined by a meta-analysis that showed that cross-cultural differences in individualism and collectivism depended on the facets of these constructs used in the study (Oyserman et al. 2002). With respect to collectivism, especially the following aspects were relevant for detecting cultural differences: aspects of harmony, defining the self within the context, and acceptance of hierarchy. Because collectivism involves orientation toward an in-group (Oyserman et al, 2002; Triandis, 1994), it seems important to refer to specific in-groups such as the family. Therefore, we decided to concentrate on aspects of collectivism that only concern the family. Family values are strongly related to collectivism (Hofstede, 2001; Trommsdorff, Mayer, \& Albert, 2004) and family values are most relevant for our research questions.

Cultures high in family values emphasize the interdependence of family members; an independently defined self is not highly valued. In addition, family relations are more likely to be hierarchical, and family members are expected to show loyalty toward the family and respect and obedience to the older generations (Georgas, Berry, van de Vijver, Kagitcibasi, \& Poortinga, 2006; Hofstede, 2001; Trommsdorff, 2006).

A few studies have underlined the importance of positive parent-child relationships for adolescents' life satisfaction in cultures high in family values. For example, among Chinese early adolescents, parental warmth was associated with higher life satisfaction (Leung, Wong, Wong, \& McBrideChang, 2010). Based on longitudinal data, maternal warmth was positively related to an increase in life satisfaction across early adolescence (Leung, McBride-Chang, \& Lai, 2004). These results are in line with the assumptions of the Parental Acceptance-Rejection Theory (Rohner, 1986): Parental acceptancecomprising warmth, support, and estimation - is assumed to be universally positively associated with psychosocial adjustment of children and adolescents (Khaleque \& Rohner, 2002).

It seems, however, that the relevance of peer group integration or peer acceptance for early adolescents' life satisfaction in cultures high in family values has not yet been investigated. Peer groups in East Asia do not function to achieve independence from the family in adolescent development as much as in Western cultures (Chen, Chang, \& He, 2003; Leung, 1996), so they may be more relevant for socialization and adapting to cultural norms. In a similar vein, Nsamenang (2002) summarized that peers in Sub-Saharan Africa function to socialize adolescents with respect to norm orientation. For India, Verma and Saraswathi (2002) concluded that peers are less important for adolescents as compared to family. Thus, the function of peers in cultures high in family 
values differs from that in Western cultures where the main function of the peer group is to fulfill individual needs of individuation, identity development, and intimacy. It seems, for cultures high in family values, there is less importance associated with integrating in a peer group. This might be reflected by the finding that adolescents in Asian samples spend less time with peers than do adolescents from the United States and Europe (see Larson, \& Verma, 1999). However, in the only study that has investigated links between peer acceptance and subjective well-being (SWB) from a cross-cultural perspective, no difference was found between older Chinese and U.S.-American adolescents for the relation between peer acceptance and an affective facet of SWB, depressive symptoms (Greenberger, Chen, Tally, \& Dong, 2000).

To our knowledge, only one study to date has investigated the influence of cultural values (here, individualism) on the association between (a) aspects of parents and peer relationships and (b) life satisfaction. This study involved an older population of junior college students from 31 nations (Diener \& Diener, 1995). The authors showed that the lower the individualism at the cultural level, the weaker the connection was between satisfaction with friends and general life satisfaction. However, the correlation between family satisfaction and life satisfaction did not depend on culture-level individualism. Thus, culture may affect the importance of parent and peer relationships differently. Nevertheless, Larson and Verma (1999) concluded in their review that the developmental relevance of cultural differences in relationships with parents and peers is still unknown.

In sum, the aim of our study is to investigate how culture-level family values affect the individual-level effects of relationship quality with parents and peer acceptance on early adolescents' life satisfaction. Therefore, multilevel analyses were conducted (Nezlek, 2010). Our expectation concerning peer acceptance was based on the varying role of peers in cultures preferring traditional family values versus cultures emphasizing adolescents' individuation. We expected that the stronger the culture-level traditional family values, the weaker the associations would be between peer acceptance and early adolescents' life satisfaction. Warm and accepting parent-adolescent relationships seem to be important in every culture (Diener \& Diener, 1995; Kaleque \& Rohner, 2002). Therefore, we expected to find positive relations between aspects of parental warmth and early adolescents' life satisfaction independent of cultural values. Given that in cultures high in traditional family values individuation from the family is not supported (Georgas et al., 2006; Trommsdorff, 2006), we expected a different pattern for aspects of the parent-adolescent relationship that are related to a change from a hierarchical towards a partner-like relationship, such as self-disclosure, a facet of 
intimacy. Therefore the higher the traditional family values in a culture, the weaker the association between intimacy and life satisfaction. The present study attempts to overcome some of the shortcomings of the previous research presented above by comparing young adolescents from cultures representing a wide range of sociocultural factors. Further, we explicitly consider family values at the cultural level in order to contribute to a culturally sensitive exploration of factors important for life satisfaction in early adolescence.

\section{Method}

\section{Participants}

This study is part of the cross-cultural study "Value ofChildren and Intergenerational Relations" (VOC study; Trommsdorff \& Nauck, 2005), which has been carried out in 15 nations. The VOC study is a three-generation study that includes about 300 early-to-middle adolescents, their mothers, and about 100 maternal grandmothers in each of the countries studied. Following the requirements of crosscultural research, we included countries from diverse geographical regions, which represent a wide range of cultural orientations toward family norms. In cultures where strong urban-rural differences continue to exist (i.e., China, India, Indonesia, Poland, South Africa, Turkey), samples from both rural and urban areas were included. In all other cultures, adolescents were recruited from suburban or urban regions. The sampling was restricted to only a few locations within each country. Nevertheless, in China, France, Germany, Poland, and Turkey the samples came from several regions varying in geographical and socioeconomic characteristics. In India, Indonesia, Israel, Russia, South Africa, and the United States, the samples came only from one region but still with varying socioeconomic characteristics. ${ }^{1}$ In multiethnic countries (Indonesia, Israel, South Africa, USA) ethnical homogeneous samples were collected because the samples sizes did not allow for further differentiations. ${ }^{1}$

The procedures of recruitment were adapted to the specific circumstances of the respective country. In most countries, families were recruited through the schools of the target adolescents (China, France, India, Indonesia, Poland, Russia, and the United States). Participants were also chosen through resident registration lists (rural China, Germany, rural India), by a random selection from telephone books (Israel) or by a multistage cluster procedure (South Africa). The data collection of the VOC core cultures (China, Germany, India, Indonesia, Israel, South Africa, Turkey) took place in the years 2002 and 2003. In France, the data were collected between 2002 and 2004, in Poland and the United states between 2005 and 2007, and in Russia in the years 2006 and 2007. 
Table I. Means and Standard Deviations of Adolescents' Age and of Culture-Level Indicators of Family Orientations

\begin{tabular}{lrcccc}
\hline Culture & N & $\begin{array}{c}\text { Adolescents } \\
\text { age, } M(S D)\end{array}$ & Females \% & $\begin{array}{c}\text { Traditional } \\
\text { values, }{ }^{a} M\end{array}$ & $\begin{array}{c}\text { Family } \\
\text { values } \\
\text { b }\end{array}$ \\
\hline China & 246 & $13.46(0.64)$ & 58 & -1.20 & $4.27(0.49)$ \\
France & $3 \mathrm{I}$ & $13.71(0.53)$ & 74 & -.52 & $4.03(0.55)$ \\
Germany & $4 \mathrm{I}$ & $13.90(0.30)$ & 49 & $-1.35^{\mathrm{c}}$ & $4.14(0.38)$ \\
India & $5 \mathrm{I}$ & $13.96(0.20)$ & 65 & 0.52 & $4.77(0.45)$ \\
Indonesia & 74 & $13.93(0.25)$ & 54 & 1.07 & $4.62(0.30)$ \\
Israel & 56 & $13.59(0.53)$ & 59 & -0.26 & $4.47(0.62)$ \\
Poland & 179 & $13.54(0.77)$ & 60 & 0.43 & $4.27(0.59)$ \\
Russia & 38 & $13.71(0.65)$ & 60 & -1.09 & $4.17(0.56)$ \\
South Africa & 128 & $13.77(0.43)$ & 57 & 1.09 & $4.72(0.40)$ \\
Turkey & 121 & $13.63(0.58)$ & 51 & 0.86 & $4.34(0.62)$ \\
USA & 69 & $13.74(0.50)$ & 61 & 0.52 & $4.14(0.63)$ \\
\hline
\end{tabular}

a. Derived from the World Value Survey, positive values refer to a more traditional orientation; standard deviation was not reported.

b. Aggregated from reports of the adolescents of the VOC study.

c. Sample weighted mean of the values of East Germany (-I.I7) and West Germany (-I.44).

For the present study, we only refer to samples of early adolescents between 10 and 14 years of age from 11 cultures. Four cultures from the original study were not included because of missing data on relevant variables or because no early adolescents were interviewed. A total of $N=1,034$ (58\% female) adolescents participated in the study: China $(n=246)$, France $(n=31)$, Germany $(n=41)$, India $(n=51)$, Indonesia $(n=74)$, Israel $(n=56)$, Poland $(n=179)$, Russia $(n=38)$, South Africa $(n=128)$, Turkey $(n=121)$, and the United States $(n=69)$.

The mean age in the sample was 13.62 years $(S D=0.60$ years $)$ with significant differences between the 11 cultures, $F(10,1,027)=8.50, p<.001$. The means and standard deviations of age per culture are shown in Table 1. Post-hoc Bonferroni tests $(p<.05)$ revealed that the adolescents from Indonesia and India were significantly older than the adolescents from China, Israel, Poland, and Turkey. Age in the Chinese sample was significantly lower than in the German, South African, and U.S.-American samples and the Polish adolescents were significantly younger than the German, South African, and Turkish adolescents. The samples did not differ in the distribution of gender, $\chi^{2}(10, N=1,034)=9.07, p>.05$. 
Given the young age of the participants, almost all adolescents went to school at the time of the interview (100\% of the French, German, Israeli, Polish, U.S.-American adolescents). Among the remaining countries, $n=7$ Indian adolescents, $n=1$ Chinese adolescent, $n=1$ Russian adolescent, $n=1$ South African adolescent, $n=2$ Indonesian adolescents, and $n=4$ Turkish adolescents did not attend school anymore. For those cultures with samples from both rural and urban areas, the percentages of urban adolescents were: China $48 \%$, India $24 \%$, Indonesia 50\%, Poland $62 \%$, South Africa $44 \%$, and Turkey $52 \%$. In the following, the analyses were controlled for adolescent's age, gender, and region (rural or urban).

\section{Procedure}

Adolescents completed the VOC study questionnaire for adolescents (Trommsdorff, Nauck, Schwarz, Chakkarath, \& Schwenk, 2002). This standardized questionnaire contained questions concerning sociodemographic characteristics, the parent-child and grandmother-child relationships, parenting, attachment, exchange of support between the generations within the family, adolescents' family-related values and self-construals, their subjective well-being, peer relationships, and future plans. All language versions were translated from the original English version into the respective target language by a bilingual native speaker of the target language. The questionnaires were then back translated and inconsistencies were corrected in cooperation with the translators from the respective cultures. The data collection was comparable in all countries: Adolescents filled out the questionnaires in a separate place while trained female interviewers carried out the standardized face-to-face interviews with the mothers of the adolescents.

\section{Indicators at the Individual Level}

The rate of missing data in the questionnaires was very low; with respect to the items used in the following analyses the rate was $7 \%$. Further, all indicators were calculated as mean values of the respective items, resulting in $2 \%$ missing data.

Following a procedure suggested by Van de Vijver and Leung (1997), we tested the structural equivalence of the indicators across cultures. Factorial agreement between each culture's factor solution and the pooled solution across all cultures was tested using Tucker's Phi coefficients. Phi coefficients higher than .95 indicate factorial invariance, and coefficients between .90 and .95 indicate acceptable similarity. 
Parent-adolescent relationship. Two characteristics of the perceived relationship with mothers and fathers were adopted from the Network of Relationships Inventory (NRI; Furman \& Buhrmester, 1985): Intimacy (e.g., "How often do you tell your mother/father everything that is on your mind?"; Cronbach's as .63-.90; Tucker's Phis all $\geq .99$ ) and admiration (e.g., "How often does your mother/father let you know that you are good at many things?"; Cronbach's $\alpha$ s .76-.90; Tucker's Phis all $\geq .99$ ). For each scale, the adolescents rated six items on a 5-point scale ranging from 1 (never) to 5 (always). Based on a problem with one item, the reliability and Tucker's Phi for the French adolescents were too low. Thus, we decided to delete this item in the French sample, which resulted in a satisfying Cronbach's $\alpha(.86)$. Whereas admiration assesses aspects of warmth, acceptance, and esteem, intimacy refers to self-disclosure, a partner-like aspect of the parent-child relationship that is more characteristic of Western cultures (Trommsdorff \& Schwarz, 2007).

Peer acceptance. Here, we refer to one aspect of peer relationships: the perceived Peer Acceptance (Epstein, 1983; e.g., "People my age like to ask me to hang out with them."). Items were rated on a 5-point scale ranging from 1 (strongly disagree) to 5 (strongly agree). The internal consistency of the seven items was satisfactory (Cronbach's $\alpha$ s .61-.81; Tucker's Phis $\geq .97$, in South Africa, .92).

Life satisfaction. Adolescents reported on their well-being with one item concerning their general life satisfaction (Diener, Gohm, Suh, \& Oishi, 2000): “All things considered, how satisfied are you with life these days?" To overcome the problem of the questionable reliability of 1-item indicators, we also included four items on domain-specific satisfaction (friendship, family, school, and health; Henrich \& Herschbach, 1995). Adolescents rated the items on a 5-point scale ranging from 1 (not satisfied at all) to 5 (very satisfied). The internal consistency was satisfactory (Cronbach's as .60-.78, except for Germany with $\alpha=.53$; Tucker's Phis all $\geq .96$ ). Thus, we aimed for an integrative indicator of life satisfaction across a broad set of contexts and living conditions that was comparable to those used in other studies in the field (for a review, see Huebner, 2004) and further that comprised both dimensions of the cognitive component of subjective well-being, namely general and domain-specific life satisfaction (Diener et al., 2003).

\section{Culture-Level Indicators of Family Values}

Here, we focused on two different indicators that characterize family values on a cultural level. Both indicators refer to family values although each with a specific emphasis, allowing for a broader view on this construct. Further, one 
indicator refers to values of adults, the other to values of adolescents. Thus, we can investigate whose values on a cultural level are more important.

First, we characterized the 11 cultures with respect to the dimension Traditional Values from the World Value Survey (WVS; World Value Survey Association, 2009). This indicator was chosen because it comprises main aspects of traditional family values such as importance of the family, respect of hierarchy, and children's obedience. The original scale was inversely recoded by the authors. After recoding, in cultures with high (positive) values on this indicator religious values, national pride, strong parent-child ties, hierarchy, and traditional family values are important. In cultures with low (negative) values on this indicator these values are not important (see Table 1 for the means from the WVS). Here, we used information that reflects the value orientation of the adult population in the given country.

Second, we used an indicator aggregated from reports of the adolescents in our study. We used five items from the Family Values Scales (Georgas, 1991), which refer to high feelings of family obligations, approval of children's obedience, and orientation toward the family instead of individuation (e.g., "A family's problems should be solved within the family."; "Children should obey their parents."). Adolescents rated the five items on a 5-point scale ranging from 1 (strongly disagree) to 5 (strongly agree). The means and standard deviations per culture are documented in Table 1.

\section{Results}

Zero-order correlations of the individual-level indicators and the control variables (adolescents' gender, age, and region) used in the study are presented in Table 2. Further, the two culture-level independent variables Traditional Values and Family Values were substantially positively related $(r=.63, p<.05)$, and both were also positively related to the cultural means of our dependent variable Life Satisfaction (for Traditional Values: $r=.78$, $p<.01$; for Family Values: $r=.83, p<.01$ ).

\section{Statistical Procedure and Model Building}

We applied multilevel random coefficient modeling (Kreft \& de Leeuw, 1998; Luke, 2004; Raudenbush \& Bryk, 2002) to test culture-level effects of family-related value orientations and individual-level effects of (a) relationship quality with parents and (b) peer acceptance on adolescents' life satisfaction. Of special interest are the cross-level interactions between the culture-level predictors and the individual-level predictors: How do 
Table 2. Zero-order Correlations Among the Individual-Level Variables Used in the Study

\begin{tabular}{|c|c|c|c|c|c|c|}
\hline & I & 2 & 3 & 4 & 5 & 6 \\
\hline I. Gender ${ }^{\mathrm{a}}$ & 一 & & & & & \\
\hline 2. Age & -.01 & - & & & & \\
\hline 3. Region ${ }^{\mathrm{b}}$ & -.03 & $.08 * *$ & - & & & \\
\hline 4. Intimacy with parents & .01 & -.07 米 & .03 & - & & \\
\hline 5. Admiration from parents & -.01 & $-.06 * *$ & .05 & $.58 * * * * *$ & - & \\
\hline 6. Peer acceptance & .03 & .01 & .05 & $.10 * * *$ & $.16^{* * * * *}$ & 一 \\
\hline 7. Life satisfaction & -.04 & .00 & $-.08 * *$ & $.25^{* * * * *}$ & $.34 * * * *$ & $.26 * * * *$ \\
\hline
\end{tabular}

Note. $N=1028-1038$.

a. Boys coded as 0 , girls as I.

b. Rural coded as 0 , urban as I. Because the variables Intimacy with Parents, Admiration from Parents, and Peer Acceptance were entered group centered in the HLM analyses, they were standardized per culture before computing the correlations.

$* p<.10 . * * p<.05 . * * * p<.01$. ${ }^{* * * *} p<.001$.

culture-level family values affect the individual-level effects of relationship quality with parents and peer acceptance on life satisfaction? We entered the individual-level predictors group centered to remove all culture-level variance from the individual-level predictors. Thus, the regression coefficients of the individual-level predictors represent the respective within-culture average effect across all cultures. As control variables, at the individual-level adolescents' gender, age, and region (rural vs. urban; all cultures without this distinction were coded as urban) were included (uncentered, fixed effects).

Because the two culture-level predictors were substantially correlated at the cultural level, separate multilevel models were computed for each of the two culture-level predictors to avoid collinearity effects.

In a multilevel model with three predictors at the individual level (in the following we do not regard the control variables) and one predictor at the cultural level (separate models for each of the two culture-level predictors), two different kinds of regression equations are estimated. First, at the individual level (Level 1), adolescents' life satisfaction (LS) is regressed on adolescents' reported intimacy with parents (IP), perceived admiration from parents (AP), and their reported peer acceptance (PA) where $j$ indicates the culture, $i$ the adolescent within a culture, $\beta$ the regression weights at the individual level, and $r$ the error term at the individual level:

$$
\mathrm{LS}_{i j}=\beta_{0 j}+\beta_{1 j} \mathrm{IP}+\beta_{2 j} \mathrm{AP}+\beta_{3 j} \mathrm{PA}+r_{i j}
$$


Second, at the cultural level, the regression weights of the individual-level equation $\left(\beta_{0 j}, \beta_{1 j}, \beta_{2 j}, \beta_{3 j}\right.$; i.e., the cross-cultural variation in these regression weights) are regressed on each of the two culture-level predictors, traditional values (TV) and family values (FV), in separate models where $j$ indicates the culture, $\gamma$ the regression weights at the cultural level, and $u$ the error term at the cultural level:

$$
\begin{aligned}
& \beta_{0 \mathrm{j}}=\gamma_{00}+\gamma_{01} \mathrm{TV} / \mathrm{FV}+\mathrm{u}_{0 \mathrm{j}} \\
& \beta_{1 \mathrm{j}}=\gamma_{10}+\gamma_{11} \mathrm{TV} / \mathrm{FV}+\mathrm{u}_{1 \mathrm{j}} \\
& \beta_{2 \mathrm{j}}=\gamma_{20}+\gamma_{21} \mathrm{TV} / \mathrm{FV}+\mathrm{u}_{2 \mathrm{j}} \\
& \beta_{3 \mathrm{j}}=\gamma_{30}+\gamma_{31} \mathrm{TV} / \mathrm{FV}+\mathrm{u}_{3 \mathrm{j}}
\end{aligned}
$$

The use of the slash between TV and FV denotes that either traditional values or family values are included in separate models. Thus, with regard to $\beta_{0 j}$ the question is to what degree culture-level traditional values (TV) or family values (FV), respectively, can predict the variation of adolescents' life satisfaction across cultures (i.e., the intercept) when all individual-level variables are taken into account. With regard to $\beta_{1 j}, \beta_{2 j}$, and $\beta_{3 j}$, the question is to what degree these culture-level values can explain cross-cultural differences in the regression slopes of the individual-level predictors intimacy with parents (IP), admiration from parents (AP), and peer acceptance (PA), respectively.

Following the suggestions of Luke (2004), we proceeded in a stepwise fashion starting with the variance component model or null model (only intercepts and error terms at both levels). Next, a model with only individuallevel predictors was estimated, followed by adding the culture-level predictors in the final model. For the multilevel analysis, the program HLM 6 was used (Raudenbush, Bryk, Cheong, Congdon, \& du Toit, 2004) and restricted maximum likelihood estimation was applied.

The model presented above is the generic multilevel model with random errors at the cultural level (Luke, 2004). This allows us to test (a) whether there is significant variation in the individual-level coefficients across cultures and (b) whether the variation remains significant after including the culture-level predictors, which should explain this variation according to our hypothesis.

\section{Null Model and Individual-Level Model}

The results of the null model showed a significant between-variance component of $u_{0 j}=.0249, \chi^{2}(10)=91.14, p<.001$, and a residual within-variance component of $r_{i j}=.3296$. Thus, the proportion of the between-variance 
component to the overall variance in the model (intraclass correlation, ICC) was .0702 , reflecting that about $7 \%$ of the overall variance in adolescents' life satisfaction was due to cross-cultural differences.

In the next step, we used the variables Intimacy with Parents, Admiration from Parents, and Peer Acceptance as well as the control variables Gender, Age, and Region as predictors at the individual level (see Table 3, Model 1). The results of this individual-level model showed a nonsignificant effect of Intimacy with Parents on adolescents' Life Satisfaction $\left(\gamma_{10}=0.05, n s\right)$ with a trend level significant variance component $\left(u_{1 j}=.0041, p<.10\right)$, pointing to culturally different slopes of this predictor. The effect of Admiration from Parents on Life Satisfaction was positively significant $\left(\gamma_{20}=0.20, p<.001\right)$ while its variance component was nonsignificant $\left(u_{2 j}=.0030, n s\right)$. Thus, perceived higher admiration from parents was related to higher life satisfaction similarly in all cultures. Finally, Peer Acceptance was significantly positively related to Life Satisfaction $\left(\gamma_{30}=0.21, p<.01\right)$, and this individual-level slope also varied significantly across cultures $\left(u_{3 j}=.0150, p<.01\right)$. With regard to the control variables in the model, Gender had a significant negative effect $\left(\gamma_{40}=\right.$ $-0.07, p<.05)$ indicating slightly lower life satisfaction for girls as compared to boys, whereas the effect of Age was nonsignificant $\left(\gamma_{50}=-0.03, n s\right)$. The effect of Region was significantly negative $\left(\gamma_{60}=-0.12, p<.01\right)$, indicating a lower life satisfaction in urban as compared to rural adolescents.

To summarize the results of the individual-level model, Admiration from Parents was positively related to adolescents' Life Satisfaction and this effect did not vary significantly across cultures. Intimacy with Parents was unrelated to Life Satisfaction on average across all cultures, but this effect showed trend-level significant variation across cultures. Finally, Peer Acceptance was positively related to Life Satisfaction, the strength of this effect varied significantly across cultures.

\section{Adding Culture-Level Predictors}

In the next step, we added culture-level predictors to explain the individuallevel variation of slopes across cultures. Because the slope of Admiration from Parents did not vary significantly, this slope was fixed and no culturelevel predictors were included. We included culture-level predictors for the slope of Intimacy with Parents, even though this slope showed only trendlevel significant variation. This was done because the power of the significance test to detect varying slopes at Level 1 (random effects) is lower than the power to detect effects of Level 2 predictors on these slopes (fixed effects), especially in our case with a small number of Level 2 units (cultures). 


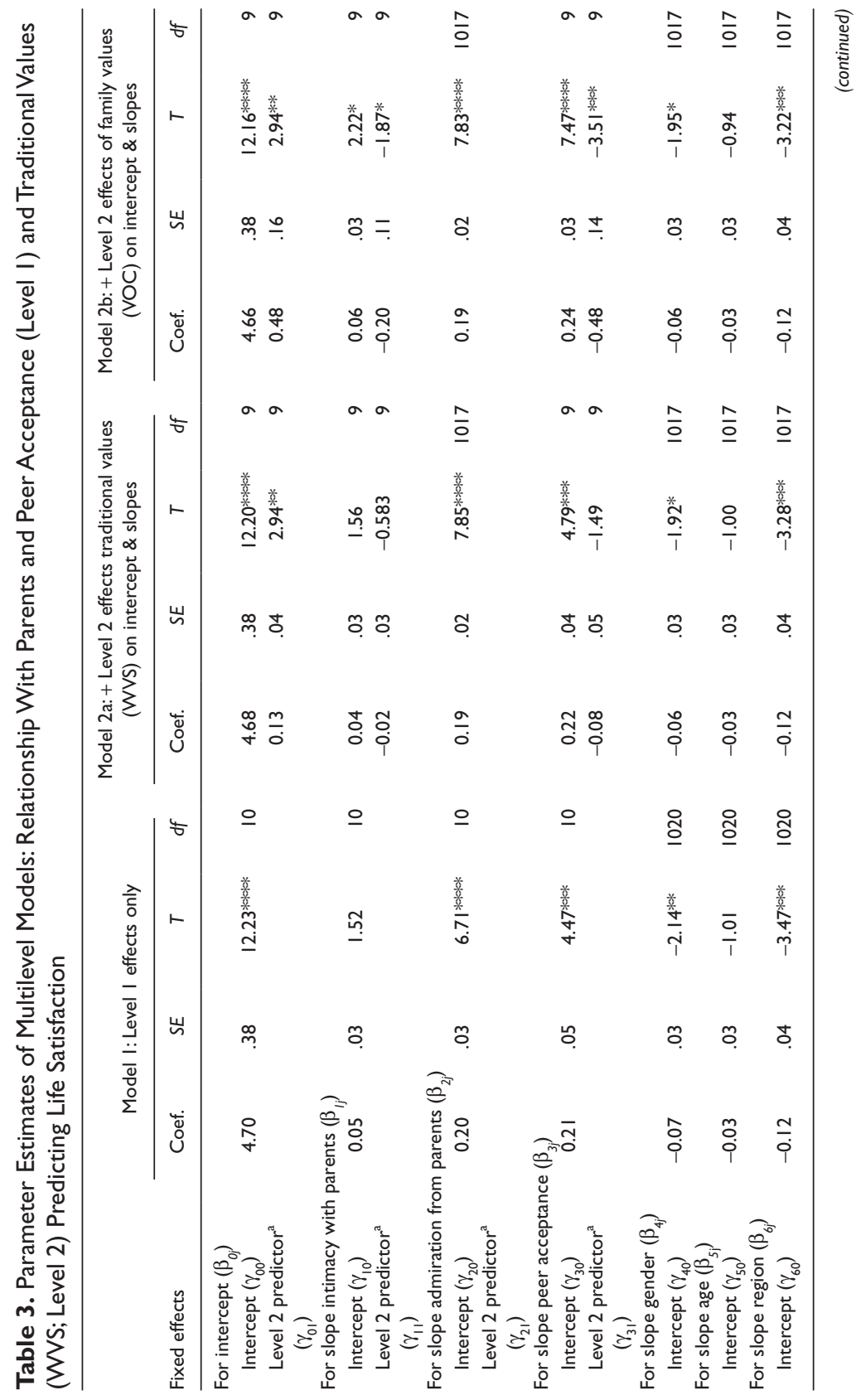




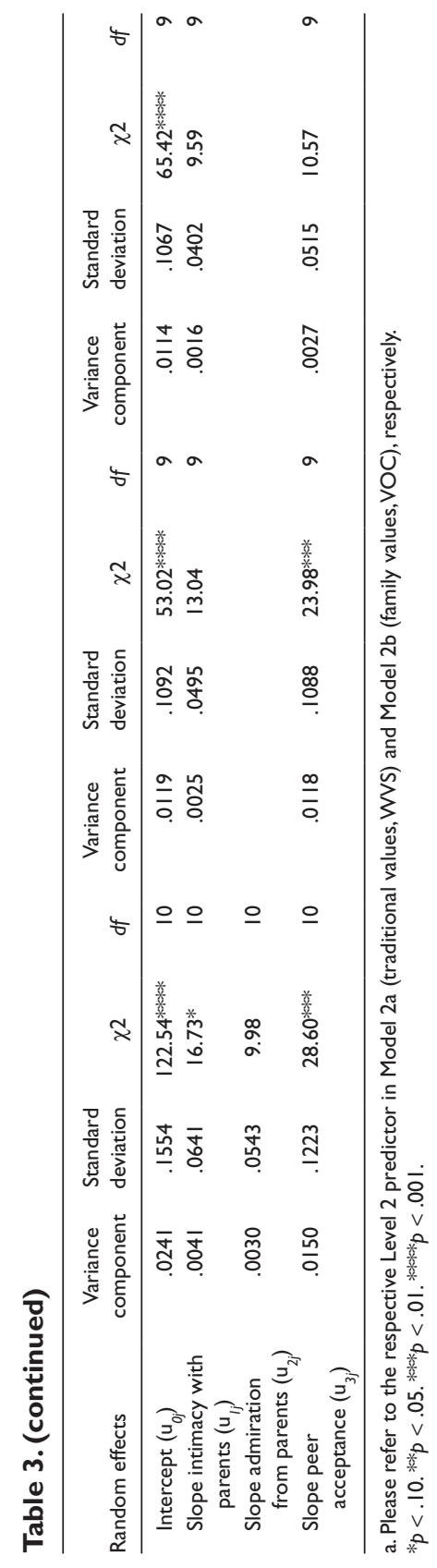


Traditional values (WVS). The results show that at the cultural level Traditional Values were significantly related to adolescents' Life Satisfaction $\left(\gamma_{01}=0.13, p<.05\right)$ indicating that in cultures characterized by higher traditional values, adolescents were more satisfied with their lives than were adolescents in cultures characterized by lower traditional values (see Table 3, Model 2a). With regard to the crucial cross-level interactions, the effect of Traditional Values on the slopes of both individual-level predictors was nonsignificant (Intimacy with Parents: $\gamma_{11}=-0.02, n s$; Peer Acceptance: $\gamma_{31}=$ $-0.08, n s)$. The variance component of Intimacy with Parents was nonsignificant in this model $\left(u_{l j}=.0025, n s\right)$, and the variance component of Peer Acceptance was still significant $\left(u_{3 j}=.0118, p<.01\right)$. Thus, culture-level Traditional Values did not affect the way in which the relationship quality with parents and peer acceptance were related to adolescents' life satisfaction across cultures.

Family values (VOC). At the cultural level, Family Values were significantly related to adolescents' Life Satisfaction $\left(\gamma_{01}=0.48, p<.05\right)$, indicating that adolescents in cultures characterized by higher family values were more satisfied with their lives than were adolescents in cultures characterized by lower family values (see Table 3, Model 2b). With respect to cross-level interactions, the effect of Family Values on the individual-level slope of Intimacy with Parents was significant only at a trend level $\left(\gamma_{11}=-0.20, p<.10\right)$. Family Values had a significant negative effect on the slope of Peer Acceptance $\left(\gamma_{31}=-0.48, p<.01\right)$, indicating that the positive effect of Peer Acceptance on adolescents' Life Satisfaction was weaker in cultures that place greater importance on Family Values than it is in cultures that place less importance on Family Values. In this model, the variance components of Intimacy with Parents $\left(u_{l j}=.0016, n s\right)$ and the variance component of Peer Acceptance were not any more significant $\left(u_{3 j}=.0027, n s\right)$.

To summarize, culture-level Family Values had a significant effect on the way in which peer acceptance was related to adolescents' life satisfaction across cultures: the higher the family values on average in a culture, the weaker the positive association of Peer Acceptance and Life Satisfaction was in the respective culture.

\section{Discussion}

The aim of the study was to investigate whether the associations between (a) the quality of the parent-child relationship and peer acceptance and (b) early adolescents' life satisfaction differed depending on the importance of family values in the respective culture. The analyses revealed a positive relation between 
parental admiration of the adolescents and adolescents' life satisfaction across all cultures. Further, the more important family values in the respective culture, the lower was the association between peer acceptance and adolescents' life satisfaction. In the following, the findings are discussed in detail.

In the present study, the individual-level effects showed that both perceived admiration from parents and peer acceptance were positively related to adolescents' life satisfaction across cultures. These results are in line with the general notion that the quality of social relationships is important for life satisfaction (Diener et al., 1999). Here, we showed that this is the case across a number of very different cultures. Success in relationships with peers and a positive quality of the parent-child relationship are both relevant for early adolescents' well-being, independent of their cultural background.

Although there was an overall positive association between peer acceptance and life satisfaction, the strength of this individual-level effect varied significantly across the cultural contexts. This result clearly points to cultural differences in the importance of peer acceptance, at least when the aggregated adolescents' family values from the VOC study were considered. The variation can be explained by culture-level endorsement of family values: higher culture-level family values (such as India and South Africa, see also Table 1) were related to a lower importance of peer acceptance for adolescents' life satisfaction. This result is in line with Diener and Diener's (1995) study on older adolescents, which found stronger relations between satisfaction with friends and global life satisfaction in individualistic cultures. Our study adds to these findings by investigating aspects of peer relationships that are psychologically more distinct from life satisfaction than the "satisfaction with friends" measure used by Diener and Diener.

The result supports our hypothesis that peers are more important for adolescents from cultures that emphasize greater independence from the family (in our study for instance France, Germany and the United States; see Table 1): In these cultures, peers support the adolescent in detaching from parents and developing an independent identity in a cultural context of independence (Collins \& Steinberg, 2006). In cultures that emphasize family values, peer groups function to encourage the adolescent to adapt to the social norms in the culture (Chen et al., 2003; Leung, 1996; Nsamenang, 2002). These functions might not be as relevant for well-being as the function of individuation in less family-oriented cultures.

In addition, we did not find cross-cultural variation in the relation between admiration by parents and early adolescents' life satisfaction. This result is also in line with the results of Diener and Diener (1995). In their study, the association between satisfaction with family and global satisfaction was 
independent of the degree of individualism in the culture. Thus, our findings support the assumption of some authors (e.g., Khaleque \& Rohner, 2002) that parental warmth and acceptance are important for early adolescents relatively independent of the respective cultural values.

However, the association between intimacy with parents and life satisfaction of early adolescents seemed to vary across cultures, although the respective effect reached only trend-level significance. The present study could only show a tendency that these cultural differences in the effect of intimacy can be explained by cultural differences in family values. From our perspective, it remains an open question whether high intimacy (as an indicator for self-disclosure, a more partner-like behavior in the parent-child relationship) is more important for early adolescents' life satisfaction in cultures that emphasize independence from the family.

Finally, the adolescents' aggregated family values were much more powerful predictors of cross-cultural variations with respect to the role of peer acceptance for their life satisfaction than were the traditional values taken from the World Value Survey which included adult respondents. The norms and values that are reflected in the behavior and communication of peers seem to be of greater relevance to adolescents than more distant values expressed in the larger society by adults. However, this does not mean that the traditional values from the WVS were not related to the adolescents' life satisfaction at all. The high correlation of the WVS indicator and the family values aggregated across the participants of the VOC study point to a connection between adolescents' and larger society's family values.

Furthermore, both culture-level indicators were similarly related to adolescents' life satisfaction. High traditional family values at a cultural level (WVS and VOC indicators) were related to higher adolescent life satisfaction. This is contrary to the very solid finding that individuals in individualistic cultures show higher well-being (Suh \& Koo, 2008). This is often interpreted by the cultural norm of self-enhancement in individualistic cultures and the norms of modesty and self-criticism in collectivistic cultures (Kornadt, 2009). These findings as well as the interpretations of these studies refer to adult samples. In the present study, however, we investigated early adolescents for whom we do not have comparable findings from larger, representative studies. So, it remains an open question as to whether and in what respect young adolescents have been socialized to follow the prevalent cultural norms in their self-reports. Further, we did not use a measure of individualism but instead family values at the cultural level. Although the cultures in the study also represent a broad range of individualism (United States is very high in individualism; France, Germany, India, Israel, Japan, Poland, 
South Africa are in the middle; and China, Indonesia, Russia, and Turkey are rather low; Hofstede, 2001) the assignment of these cultures to individualism does not perfectly correspond to the indicators of family orientation we used (see Table 1).

With respect to the control variables, a gender difference was found; girls were less satisfied with their life than boys. In his review, Huebner (2004) came to the conclusion that there is no gender difference in life satisfaction from childhood to adolescence. However, he referred to samples from Western cultures. So, it might be that gender differences occur in nonWestern cultures. However, the effect in the present study is of small size and should not be overestimated. Early adolescents from rural areas were significantly more satisfied with life than age-mates from urban areas. This result corresponds to the above discussed result of a positive association between traditional family values and life satisfaction since individuals from rural areas hold more traditional values. Surprisingly, we did not find an age effect on life satisfaction. Two studies have shown that life satisfaction decreases from early to middle adolescence (Casas et al., 2007; Goldbeck, et al., 2007). However, the present study comprised only early adolescents representing an age range which might be too narrow to detect age effects.

\section{Study Limitations and Strength}

One limitation of the present study is the relatively low number of cultures in the analyses. Random coefficient multilevel modeling requires a substantial number of Level 2 units (cultures) to obtain reliable estimates and to have enough statistical power to detect significant relations. The 11 cultures included in the current study represent a small number of Level 2 units. Though simulation studies suggest that multilevel models with less than 30 Level 2 units can lead to biased estimates of the second-level standard errors (Maas \& Hox, 2005), Bond and van de Vijver (2010) argue that a minimum of 10 cultures may suffice for multilevel modeling. Though we are aware that questions of reliability and power remain, we are convinced that our multilevel models with relatively low numbers of Level 2 units contribute to a culturally sensitive understanding of factors relevant for early adolescents' life satisfaction. This is especially important because in cross-cultural research, large-scale studies including early adolescents from such a high number of cultures are rare.

A second limitation of the study lies in the cross-sectional character of the data because it does not allow for causal interpretations. Although our design suggests that parent and peer relationships affect adolescents' life 
satisfaction, the opposite direction of influence is also possible as two recent 1 -year longitudinal studies have shown for parent and peer relationships (Martin, Huebner, \& Valois, 2008; Saha, Huebner, Suldo, \& Valois, 2010).

Further, the unequal sample sizes might be critical. However, in order to optimize the statistical power we did not reduce the larger samples in the analyses. Due to the small sample sizes per culture and limitations of recruitment the samples cannot be considered as representative. Additionally, the small samples in some cultures are susceptible to possible outlier effects.

Further research on this topic should analyze the relations in a longer period of time. This will provide insight into possible changes in the relative importance of parents and peers across adolescence. The measure of intimacy in relation to parents comprised only one aspect of this construct, namely self-disclosure. Emotional attachment as another aspect was not covered (Shulman, Laursen, Kalman, \& Karpovsky, 1997). Results from crosscultural studies might differ from the present findings if emotional attachment is considered, since this aspect comes closer to traditional concepts of parent-child relationships. In the present study, we only measured one aspect of peer relationships, peer acceptance. The quality of the peer relations should also be considered in the future.

The present study has its strength in contributing to a better understanding of the culture-specific importance of different social relationships for life satisfaction in early adolescence. This is a developmental period for which subjective well-being has not been investigated intensively in the past. Given the strong connection between life satisfaction and both physical and mental health, our findings also have practical importance. Efforts to enhance early adolescents' life satisfaction by improving the quality of parent-child and peer relationships will be successful depending on the prevailing cultural values.

\section{Acknowledgments}

The authors are grateful to three anonymous reviewers and the editor for their helpful comments on an earlier version and to Holly Bunje for her linguistic editing.

\section{Declaration of Conflicting Interests}

The authors declared no potential conflicts of interest with respect to the research, authorship, and/or publication of this article.

\section{Funding}

The authors disclosed receipt of the following financial support for the research, authorship, and/or publication of this article: This study is part of the cross-cultural and interdisciplinary research project "Value of Children and Intergenerational 
Relations." Principal investigators: Gisela Trommsdorff, University of Konstanz, and Bernhard Nauck, Chemnitz University of Technology. For seven countries (People's Republic of China, Germany, Indonesia, Israel, Poland, Turkey, United States) the study was funded by the German Research Foundation [TR 169/9-1, -2, -3 and NA $164 / 9-1,-3,-4,-5]$. In India, the study was cofunded by the University of Konstanz and the German Research Foundation. In France, the study was funded by the University Victor Segalen, Bordeaux; in Russia it was co-funded by the Lobatchevskij State University, Nizhnij Novgorod; and in South Africa by the University of Limpopo.

\section{Note}

1. More specifically, the regions for data collection were the following: China: Beijing, Henan Province, Yunnan Province, Guangxi Zhuang Autonomous region; France: Paris and its suburban areas, Bordeaux and surroundings and from small towns in rural areas in France; Germany: Chemnitz, Essen, Konstanz; India: Varanasi City (urban) Naugarh Block of Chandauli District (rural); Indonesia: Bandung (urban) and surroundings (rural) (almost 90\% were Sundanese); Israel: Jerusalem and suburbs (the sample comprises only Jewish participants); Poland: Szczecin, Białystok, Bydgoszcz, Łodz, Czestochowa, Krakow, Wroclaw; Russia: Nizhnij Novgorod; South Africa: Limpopo Province (all participants were Black Africans); Turkey: Istanbul and two small villages from Western and Eastern Turkey; United States: Grand Rapids, MI and surrounding areas ( $98 \%$ of the participants were Whites).

\section{References}

Bond, M. H., \& van de Vijver, F. J. R. (2010). Making scientific sense of cultural differences in psychological outcomes: Unpackaging the Magnum Mysterium. In D. Matsumoto \& F. J. R. van de Vijver (Eds.), Cross-cultural research methods in psychology (pp. 75-100). New York, NY: Cambridge University Press.

Casas, F., Figuer, C., Gonzalez, M., Malo, S., Alsinet, C., \& Subarroca, S. (2007). The well-being of 12- to 16-year-old adolescents and their parents: Results from 1999 to 2003 Spanish samples. Social Indicator Research, 83, 87-115.

Chen, X., Chang, L., \& He, Y. (2003). The peer group as a context: Mediating and moderating effects on relations between academic achievement and social functioning in Chinese children. Child Development, 74, 710-727.

Chen, X., French, D. C., \& Schneider, B. H. (2006). Culture and peer relationships. In X. Chen, D. C. French, \& B. H. Schneider (Eds.), Peer relationships in cultural context (pp. 3-20). Cambridge, UK: Cambridge University Press.

Collins, W. A., \& Steinberg, L. (2006). Adolescent development in interpersonal context. In N. Eisenberg, W. Damon, \& R. M. Lerner (Eds.), Handbook of child psychology (pp. 1003-1067). Hoboken, NJ: Wiley. 
Diener, E., \& Diener, M. (1995). Cross-cultural correlates of life-satisfaction and selfesteem. Journal of Personality and Social Psychology, 68, 653-663.

Diener, E., Gohm, C. L., Suh, E., \& Oishi, S. (2000). Similarity of the relations between marital status and subjective well-being across cultures. Journal of Cross-Cultural Psychology, 31, 419-436.

Diener, E., Oishi, S., \& Lucas, R. E. (2003). Personality, culture, and subjective wellbeing: Emotional and cognitive evaluations of life. Annual Review of Psychology, $54,403-425$.

Diener, E., Suh, E. M., Lucas, R. E., \& Smith, H. L. (1999). Subjective well-being: Three decades of progress. Psychological Bulletin, 125, 276-302.

Epstein, S. (1983). The mother-father-peer scale. Unpublished manuscript. Amherst: University of Massachusetts.

Furman, W., \& Buhrmester, D. (1985). Children's perceptions of the personal relationships in their social networks. Developmental Psychology, 21, 1016-1024.

Georgas, J. (1991). Intrafamily acculturation of values in Greece. Journal of CrossCultural Psychology, 22, 445-457.

Georgas, J., Berry, J.W., van de Vijver, F. J. R. , Kagitcibasi, C., \& Poortinga, Y. H. (2006). (Eds.), Families across cultures. A 30-nation psychological study. Cambridge, UK: Cambridge University Press.

Goldbeck, L., Schmitz, T. G., Besier, T., Herschbach, P., \& Henrich, G. (2007). Life satisfaction decreases during adolescence. Quality of Life Research, 16, 969-979. Greenberger, E., Chen, C., Tally, S. R., \& Dong, Q. (2000). Family, peer, and individual correlates of depressive symptomatology among U.S. and Chinese adolescents. Journal of Consulting and Clinical Psychology, 68, 209-219.

Henrich, G. E., \& Herschbach, P. (1995). Fragen zur Lebenszufriedenheit (FLZ) - ein Gewichtungsmodell [Questions on Life Satisfaction. A weighting model.] In R. Schwarz, J. Bernhard, H. Flechtner, T. Küchler \& C. Hürny (Eds.), Lebensqualität in der Onkologie. Munich, Germany: Zuckerschwerdt Verlag.

Hofstede, G. H. (2001). Cultures consequences: Comparing values, behaviors, institutions, and organizations across nations (2nd ed.). Thousand Oaks, CA: SAGE.

Huebner, E. S. (2004). Research on assessment of life satisfaction of children and adolescents. Social Indicators Research, 66, 3-33.

Huebner, E. S., Funk, B. A., Gilman, R. (2000). Cross-sectional and longitudinal psychosocial correlates of adolescent life satisfaction reports. Canadian Journal of School Psychology, 16, 53-64.

Kagitcibasi, C. (1994). A critical appraisal of individualism and collectivism: Toward a new formulation. In U. Kim, H. C. Triandis, C. Kagitcibasi, S.-C. Choi \& G. Yoon (Eds.), Individualism and collectivism. Theory, methods, and applications (pp. 52-65). Thousand Oaks, CA: SAGE. 
Khaleque, A., \& Rohner, R. P. (2002). Perceived parental acceptance-rejection and psychological adjustment: A meta-analysis of cross-cultural and intracultural studies. Journal of Marriage and the Family, 64, 54-64.

Kornadt, H.-J. (2009). Quality of life and happiness: Transculturally comparable? In G. Széll, D. Ehrig, U. Staroske, \& U. Széll (Eds.), Quality of life and working in comparison (pp. 387-397). Frankfurt, Germany: Lang.

Kreft, I., \& de Leeuw, J. (1998). Introducing multilevel modeling. London, UK: SAGE.

Larson, R. W., \& Verma, S. (1999). How children and adolescents spend time across the world: Work, play, and developmental opportunities. Psychological Bulletin, 125, 701-736.

Leung, A. N. M., Wong, S. S. F., Wong, I. W. Y., \& McBride-Chang, C. (2010). Filial piety and psychosocial adjustment in Hong Kong Chinese early adolescents. Journal of Early Adolescence, 30, 651-667.

Leung, C. Y. W., McBride-Chang, C., \& Lai, B. P.-Y. (2004). Relations among maternal parenting style, academic competence, and life satisfaction in Chinese early adolescents. Journal of Early Adolescence, 24, 113-143.

Leung, M. C. (1996). Social networks and self enhancement in Chinese children: A comparison of self reports and peer reports of group membership. Social Development, 5, 146-157.

Luke, D. A. (2004). Multilevel modeling. Thousand Oaks, CA: SAGE.

Ma, C. Q., \& Huebner, E. S. (2008). Attachment relationships and adolescents' life satisfaction: Some relationships matter more to girls than boys. Psychology in Schools, 45, 177-190.

Maas, C. J. M., \& Hox, J. J. (2005). Sufficient sample sizes for multilevel modeling. Methodology, 1, 86-92.

Martin, K., Huebner, E. S., \& Valois, E. S. (2008). Does life satisfaction predict victimization experiences in adolescence? Psychology in Schools, 45, 705-714.

Nezlek, J. B. (2010). Multilevel modeling and cross-cultural research. In D. Matsumoto \& F. J. R. van de Vijver (Eds.), Cross-cultural research methods in psychology (pp. 299-347). New York, NY: Cambridge University Press

Nickerson, A. B., \& Nagle, R. J. (2004). The influence of parent and peer attachments on life satisfaction in middle childhood and early adolescence. Social Indicators Research, 66, 35-60.

Nsamenang, A. B. (2002). Adolescence in sub-Saharan Africa: An image constructed from Africa's triple inheritance. In B. B. Brown, R. Larson \& T. S. Saraswathi (Eds.), The world's youth. Adolescence in eight regions of the globe. (pp. 61-194). Cambridge, UK: Cambridge University Press. 
Oyserman, D., Coon, H. M., \& Kemmelmeier, M. (2002). Rethinking individualism and collectivism: Evaluation of theoretical assumptions and meta-analyses. Psychological Bulletin, 128, 3-72.

Raudenbush, S. W., \& Bryk, A. S. (2002). Hierarchical linear models. Applications and data analysis methods (2nd ed.). Thousand Oaks, CA: SAGE.

Raudenbush, S. W., Bryk, A. S., Cheong, Y. F., Congdon, R., \& du Toit, M. (2004). HLM 6: Hierarchical linear and nonlinear modeling. Lincolnwood, IL: Scientific Software International.

Rohner, R. P. (1986). The warmth dimension: Foundations of parental acceptancerejection theory. Thousand Oaks, CA: SAGE.

Rubin, K. H., Bukowski, W. M., \& Parker, J. G. (2006). Peer interactions, relationships, and groups. In N. Eisenberg, W. Damon \& R. M. Lerner (Eds.), Handbook of child psychology. Hoboken, NJ: Wiley.

Saha, R., Huebner, E. S., Suldo, S. M., \& Valois, E. S. (2010). A longitudinal study of adolescent life satisfaction and parenting. Child Indicator Research, 3, 149-165.

Shulman, S., Laursen, B., Kalman, Z., \& Karpovsky, S. (1997). Adolescent intimacy revisited. Journal of Youth and Adolescence, 26, 597-617.

Suh, E. M., \& Koo, J. (2008). Comparing subjective well-being across cultures and nations. In M. Eid \& R. J. Larsen (Eds.), The science of subjective well-being (pp. 414-427). New York, NY: Guilford.

Suldo, S. M., \& Huebner, E. S. (2004a). Does life satisfaction moderate the effects of stressful life events on psychopathological behavior in adolescence? School Psychology Quarterly, 19, 93-105.

Suldo, S. M., \& Huebner, E. S. (2004b). The role of life satisfaction in the relationship between authoritative parenting dimensions and adolescent problem behavior. Social Indicators Research, 66, 165-195.

Triandis, H. C. (1994). Theoretical and methodological approaches to the study of collectivism and individualism. In U. Kim, H. C. Triandis, C. Kagitcibasi, S.-C. Choi, \& G. Yoon (Eds.), Individualism and collectivism. Theory, methods, and applications (pp. 41-51). Thousand Oaks, CA: SAGE.

Trommsdorff, G. (2006). Parent-child relations over the life-span. A cross-cultural perspective. In K. H. Rubin \& O. B. Chung (Eds.), Parenting beliefs, behavior, and parent-child relations. A cross-cultural perspective (pp. 143-183). New York, NY: Psychology.

Trommsdorff, G., Mayer, B., \& Albert, I. (2004). Dimensions of culture in intra-cultural comparisons: Individualism/collectivism and family-related values in three generations. In H. Vinken, J. Soeters, \& P. Ester (Eds.), Comparing cultures: Dimensions of culture in a comparative perspective (pp. 157-179). Leiden, Netherlands: Brill Academic. 
Trommsdorff, G., \& Nauck, B. (2005). The value of children in cross-cultural perspective. Case studies from eight societies. Lengerich, Germany: Pabst Science.

Trommsdorff, G., Nauck, B., Schwarz, B., Chakkarath, P., \& Schwenk, O. (2002). VOC-IR Questionnaire for Adolescents. Unpublished Questionnaire. University of Konstanz and University of Chemnitz, Germany.

Trommsdorff, G., \& Schwarz, B. (2007). A study on the "Intergenerational Stake Hypothesis" in Indonesia and Germany: Adult daughters' and their mothers' perception of their relationship. Current Sociology, 55, 599-620.

Trzcinski, E., \& Holst, E. (2008). Subjective well-being among young people in transition into adulthood. Social Indicators Research, 87, 83-109.

Van de Vijver, F. J. R., \& Leung, K. (1997). Methods and data analysis for crosscultural research. Thousand Oaks, CA: SAGE.

Verma, S., \& Saraswathi, T. S. (2002). Adolescence in India: Street urchins or Silicon Valley millionaires? In B. B. Brown, R. Larson, \& T. S. Saraswathi (Eds.), The world's youth. Adolescence in eight regions of the globe. (pp. 105-140). Cambridge, UK: Cambridge University Press.

World Values Survey Association (2009). World Value Survey 1981-2008 official aggregate v.20090901. Retrieved from www.worldvaluessurvey.org

\section{Bios}

Beate Schwarz is assistant professor at the Department of Psychology, University of Basel, Switzerland. Her research interests include the effects of family processes and peer relationships on adolescents' development, intergenerational relationships in adulthood, and cross-cultural psychology.

Boris Mayer is a postdoctoral researcher and lecturer at the Department of Psychology, University of Konstanz, Germany. He is mainly interested in adolescent development across cultures (values, views of self and world, family relations, religiosity), cultural change and globalization, and cross-cultural research methods.

Gisela Trommsdorff is professor at the Department of Psychology, University of Konstanz, Germany; Research Professor, DIW Berlin ( GSOEP); President of the German-Japanese Society for Social Sciences. Her research interests include crosscultural studies on values, intergenerational relations, and development of selfregulation, prosocial motivation, and emotions.

Asher Ben-Arieh is an associate professor at the Paul Baerwald School of Social Work and Social Welfare at the Hebrew University of Jerusalem, Israel. He is also the cochair of the International Society for Child Indicators (ISCI) and editor in chief 
of the Child Indicators Research (CIR) journal. His areas of interest are indicators of children's well-being and children's role in research.

Mihaela Friedlmeier is an assistant professor at the Department of Psychology, Grand Valley State University, Michigan, USA. Her main research areas include intergenerational relationships, lifespan development, and intercultural competence.

Katarzyna Lubiewska is a postdoctoral researcher and lecturer of developmental psychology at the Department of Psychology at Kazimierz Wielki University, Poland. Her scientific interest is focused on attachment, family relations, and crosscultural studies.

Ramesh Mishra is professor of psychology at Banaras Hindu University, India. His principal interest is in acculturation and in cultural influences on human development, particularly in the field of cognitive development and schooling.

Karl Peltzer is a research director at the Human Sciences Research Council, South Africa. He is also an extraordinary professor of psychology at the Department of Psychology at the University of the Free State, South Africa. His area of interest is psychology applied to health in low and middle income countries. 